\title{
Overview of Exercise Prescription for Diabetes Patients and Its Application in Japan
}

\author{
Yuzo Sato ${ }^{1}$
}

Received: 18 December 2019 / Accepted: 22 March 2020 / Published online: 4 May 2020

(c) The Author(s) 2020

\begin{abstract}
In recent years, the Westernization of dietary habits and increasingly sedentary lifestyle have contributed to a marked increase in the number of type 2 diabetes patients. Sedentary behavior may play a significant role in the development and aggravation of type 2 diabetes. The results of various follow-up studies have demonstrated that proper diet combined with physical exercise is useful in the prevention and treatment of type 2 diabetes. A nationwide survey regarding exercise therapy for diabetes patients in Japan revealed that relatively few physicians provide patients with exercise guidance because of time constraints, that the physicians do not receive additional consultation fee, and that there is a lack of specialized physical exercise educators. Physical exercise promotes the utilization of glucose and free fatty acids in the muscles, and thus lowers blood glucose (BG) levels. Dietary restriction and physical exercise are effective in the prevention and treatment of type 2 diabetes by improving the in vivo sensitivity to insulin. Most adults with diabetes should engage in $150 \mathrm{~min}$ or more of moderate-tovigorous intensity aerobic activity per week, spread out over at least 3 days/week, with no more than two consecutive days without activity. Mild-intensity resistance training such as half squat and calf raise is recommended for elderly individuals who have decreased muscle strength and mass (sarcopenia). Prolonged sitting should be interrupted every 30 min for BG benefits, particularly in adults with type 2 diabetes. Individuals with type 2 diabetes are also encouraged to increase their total daily unstructured physical activity (daily movement).
\end{abstract}

Keywords Diabetes mellitus - Exercise prescription $\cdot$ Sedentary behavior $\cdot$ Aerobic exercise $\cdot$ Resistance exercise . Nationwide survey

\section{Introduction}

Diabetes is a worldwide pandemic. According to the International Diabetes Federation (IDF), diabetes is a growing global problem. The number of deaths due to diabetes is 1.3 million and diabetes-related expenditure in adults (20-79 years) reaches 120.3 billion in the Western Pacific Region (2017). Furthermore, the number of diabetes patients has been predicted to increase from 163 million (2019) to 212 million (2045) in the Western Pacific Region [13].

Diabetes mellitus can be classified into the following four categories: type 1 diabetes, type 2 diabetes, gestational diabetes, and specific types of diabetes due to other causes [1].

Yuzo Sato

uz-sato@mizuho-c.ac.jp

1 Aichi Mizuho College, 2-13, Shunko-cho, Mizuho-ku, Nagoya, Aichi 467-0867, Japan
In Japan and China, most diabetes patients are type 2. Decreased insulin secretion and insulin resistance play important roles in the occurrence and progression of type 2 diabetes. Insulin resistance is exacerbated by aspects of the modern, westernized lifestyle such as overeating (high-fat diet), sedentary state, and stressful daily life [27].

Several major randomized controlled trials, including the Diabetes Prevention Program (DPP) [16] and the Da Qing Diabetes Prevention Study (Da Qing Study) [21], have demonstrated that weight loss brought about by dietary restriction and physical exercise decreased the development of type 2 diabetes among obese people with impaired glucose tolerance (IGT).

\section{Sedentary Behavior Increases Diabetes Risk}

Waking sedentary behavior is characterized by an energy expenditure $\leq 1.5$ metabolic equivalents (METs), while in a sitting, reclining or lying posture [38]. 
A sedentary lifestyle indicated by TV watching is a directly-related risk for type 2 diabetes [11]. An extra hour of sedentary time was associated with a $22 \%$ increased odds ratio for type 2 diabetes. Sedentary behavior may, therefore, play a significant role in the development and aggravation of type 2 diabetes (Maastricht Study) [40].

Higher physical activity (PA) level and lower leisure sedentary behavior were inversely associated with the incidence of type 2 diabetes [12]. A strong, inverse association between the overall volume of PA and all-cause mortality was observed. This association was primarily attributable to the strong, inverse association between moderate-to-vigorous activity and mortality [19]. Interrupting prolonged sitting with brief sessions of light-intensity walking (LW) and simple resistance activity (SRA) attenuated acute postprandial glucose and insulin responses in adults with type 2 diabetes [7].

Therefore, recently, the American Diabetes Association (ADA) recommended [1] that all adults, and particularly those with type 2 diabetes, should decrease the amount of time spent in sedentary behavior (e.g., working on a computer, watching TV) by breaking up sedentary periods (>30 min) through briefly standing, walking, or performing other light physical activities.

It has been suggested that just sitting $2.5 \mathrm{~h}$ less each day would result in an extra energy expenditure of $350 \mathrm{kcal} / \mathrm{day}$, which the authors assume could translate into preventing the gain of extra pounds. Therefore, NEAT (non-exercise activity thermogenesis) is important for the prevention of obesity [28].

\section{The Beneficial Effect of Physical Activity on the Incidence of Type 2 Diabetes}

The results of various follow-up epidemiological studies have revealed that proper diet combined with physical exercise is not only useful in preventing type 2 diabetes and improving disease status, but is also effective in the prevention and treatment of all other insulin-resistance-related diseases (non-communicable diseases (NCD)/lifestyle-related diseases) by improving the in vivo sensitivity to insulin [8, $16,21,27]$.

(1) The incidence of diabetes mellitus in impaired glucose tolerance (IGT) patients during a 6-year period decreased by $31 \%$ when diet therapy alone was prescribed, by $46 \%$ when exercise therapy alone was prescribed, and by $42 \%$ when a combination of diet and exercise therapy was prescribed (Da Qing Study, China, 1997) [21].

(2) A randomized controlled clinical trial, the Diabetes Prevention Program (DPP), demonstrated that intensive lifestyle intervention reduced the incidence of type 2 diabetes by $58 \%$ compared with placebo intervention, whereas metformin intervention reduced the incidence of type 2 diabetes by $31 \%$ (USA, 2002) [16]. The DPP Outcomes Study (DPPOS) is a long-term follow-up study of the DPP study participants, investigating whether the delay in the development of diabetes observed during the DPP is sustained and assessing the long-term effects of the various interventions on the health of the subjects. Over an average 10-year followup ( 3 years for the DPP, 7 years for the DPPOS), the incidence of diabetes after randomization was reduced by $34 \%$ and $18 \%$ in subjects initially randomized to lifestyle and metformin interventions, respectively, compared with placebo. The DPP research group concluded that the prevention or delay of diabetes using lifestyle or metformin interventions persists for at least 10 years (USA, 2009) [8].

(3) Minimal weight reduction in the intervention group (less than $3 \%$ on average) lowered the relative risk to $53 \%$ over 3 years. The present lifestyle intervention program, which used existing health care resources, is beneficial in preventing diabetes in Japanese with IGT [29]. The effect of lifestyle intervention in patients with IGT on weight related to the $\beta-3$ adrenergic receptor (ADRB3) gene polymorphism Trp64Arg is illustrated in Fig. 1. The ADRB3, primarily expressed in adipose tissue, is involved in the regulation of energy metabolism. The non-carriers (control group) showed significantly greater bodyweight reduction than carriers in both the lifestyle intervention group and the usual care group, and a greater increase of high-density lipoprotein (HDL) cholesterol levels than the carriers only in the lifestyle intervention group. These findings suggest that ADRB3 polymorphisms could influence the effect of lifestyle interventions on body weight and lipid parameters in patients with IGT. This genetic information could help to identify individuals who require intensive lifestyle intervention (i.e., carrier patients should undergo more severe dietary restriction) [Japan Diabetes Prevention Program (JDPP, Japan, 2011, 2016)] [30].

(4) The relationship between long-term trends in fitness and the incidence of type 2 diabetes was investigated. Men in the lowest quartile of the distribution decreased in fitness over 7 years (median slope $-1.25 \mathrm{~mL} / \mathrm{kg} / \mathrm{min}$ ), whereas men in the highest quartile increased in fitness (median slope $1.33 \mathrm{~mL} / \mathrm{kg} / \mathrm{min}$ ). Use of the lowest quartile, the HRs $(95 \% \mathrm{CI})$ for the second through fourth quartiles were 0.64 (0.46-0.89), $0.40(0.27-0.58)$, and $0.33(0.21-0.50)$, respectively $\left(P_{\text {trend }}<0.001\right)$. These results indicated that the long-term trend 
Fig. 1 Effect of lifestyle intervention in patients with IGT on body weight related to $\beta 3 \mathrm{AR}$ gene polymorphism Trp64Arg (C/T) (JDPP)

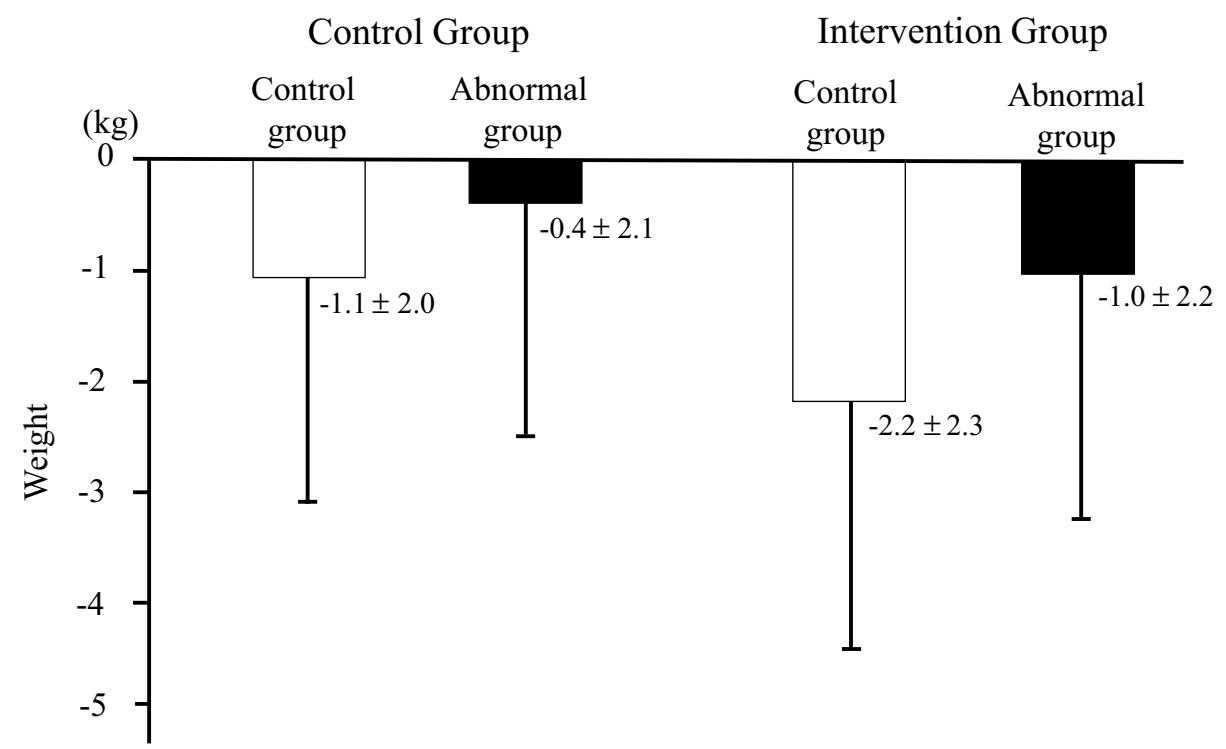

ADRB3 polymorphisms could influence the effect of lifestyle intervention on body weight in IGT. IGT: Impaired glucose tolerance.

(Drew from reference [33]) in fitness is a strong predictor of the incidence of type 2 diabetes in Japanese men (Tokyo Gas Study, Japan, 2010) [34].

(5) The association between leisure-time physical activity (LTPA) and cardiovascular events and total mortality in a nationwide cohort of Japanese diabetic patients was investigated. The 1702 eligible patients with type 2 diabetes from 59 institutes were followed for a median of 8 years. LTPA of 15.4 MET h/week or more was associated with a significantly lower risk of stroke partly through ameliorating combinations of cardiovascular risk factors. It was also associated with significantly reduced total mortality, but independently of cardiovascular risk factor or events. These findings, implying differences from Western diabetes populations, should be considered in the clinical management of East Asians with diabetes [Japan Diabetes Complications Study (JDCS, Japan, 2013)] [36].

(6) The association between habitual physical activity (PA) and lowered risk of all-cause mortality (ACM) and cardiovascular disease (CVD) has been suggested in patients with diabetes. The meta-analysis conducted by Kodama et al. [17] summarized the risk reduction in relation to PA, focusing on clarifying dose-response associations. More PA was associated with a larger reduction in future ACM and CVD risk in patients with diabetes. Nevertheless, any amount of habitual PA was shown to be better than inactivity.
(7) Lifestyle interventions are the foundation of treatment in newly diagnosed type 2 diabetes. The efficacy of the Telemedical Lifestyle intervention Program (TeLiPro) in improving metabolic control in advanced-stage type 2 diabetes was evaluated. In advanced-stage type 2 diabetes, the TeLiPro can improve glycemic control and may offer new options to avoid pharmacological intensification (Telemedical Lifestyle intervention Program [Telemedical Lifestyle intervention Program (TeLiPro, Germany, 2017)] [14].

\section{Effects of Physical Exercise}

\section{Acute Effects}

(1) Insulin-stimulated blood glucose (BG) uptake into skeletal muscle predominates at rest and is impaired in type 2 diabetes, while muscular contractions stimulate BG transport via a separate, additive mechanism (AMPK) not impaired by insulin resistance or type 2 diabetes $[6,23]$.

During physical exercise, the glucose uptake by the working muscles rises 7-20 times over the basal level depending on the intensity of the work performed. Therefore, if diabetes patients practice physical exercise after meals, the rapid increase of BG is prevented, resulting in favorable control of diabetes. However, intense exercise may cause hyperglycemia [41]. 
(2) Moderate aerobic exercise acutely improves BG and insulin action [6].

Mild-intensity post-meal walking for $15 \mathrm{~min}$ is effective for glucose homeostasis and easy to perform in the activities of the daily life of type 2 diabetes patients [9] (Fig. 2).

(3) A combination of aerobic and resistance exercise training may be more effective in improving $\mathrm{BG}$ control than either alone [35].

(4) PA can result in acute improvements in systemic insulin action, lasting from 2 to $72 \mathrm{~h}$ [3].

\section{Chronic Effects}

(1) Both aerobic and resistance training improve insulin action, BG control, and fat oxidation and storage in muscle $[6,13]$.

Even mild physical exercise that does not affect $\mathrm{VO}_{2 \max }$ can lead to improvement in the in vivo insulin sensitivity, as estimated by the glucose clamp technique if continued for a prolonged period of time [25]. The implementation of dietary restriction and physical exercise in obese people and obese patients with type 2 diabetes will result in an elective decrease of body fat, leading to weight loss, and improvement in the metabolic condition of obese type 2 diabetes while inducing no changes for lean body mass (Fig. 3). Thus, dietary restriction combined with physical exercise is more useful for improving insulin sensitivity than dietary restriction alone. In addition, increased glucose metabolic clearance rate $(\triangle \mathrm{MCR})$ shows a positive correlation with the number of steps performed per day determined by a pedometer [43]. Visceral fat, rather than subcutaneous fat, promotes the formation of insulin-resistance-related atherosclerosis.
The decrease in adipose tissue as a result of exercise is more striking in visceral than in subcutaneous adipose tissue [10].

(2) Resistance exercise enhances skeletal muscle mass [6, 42].

Aerobic exercise such as jogging is more effective for improving in vivo insulin sensitivity than anaerobic exercise like weightlifting. However, mild intensity resistance training, if carried out in an aerobic manner, is also beneficial for elderly patients who have decreased muscular strength and mass (sarcopenia) [15, 37].

(3) The implementation of exercise brings about a decrease in plasma triglyceride level, an increase in HDL cholesterol, and improvement of mild hypertension. Thus, physical exercise exerts an inhibitory effect on the development and progression of atherosclerosis through a number of mechanisms $[13,27]$.

(4) Greater level of PA and body fitness are associated with a lower risk of all-cause and CV mortality [17].

(5) Increased PA and physical fitness can reduce symptoms of depression and improve health-related QOL in individuals with type 2 diabetes [47].

The effect of exercise manifested by improved insulin sensitivity decreases within 3 days after exercise and is almost no longer apparent after 1 week [24]. Therefore, diabetes patients should engage in physical exercise at least 3 days per week, with no more than two consecutive days between bouts of PA [1].

\section{High-Intensity Interval Training (HIIT)}

High-intensity interval training (HIIT) can be described as "brief intervals of vigorous activity interspersed with
Fig. 2 The 24-h glycemic profile of a representative case on non-exercise day (dotted line) and on exercise day (solid line)

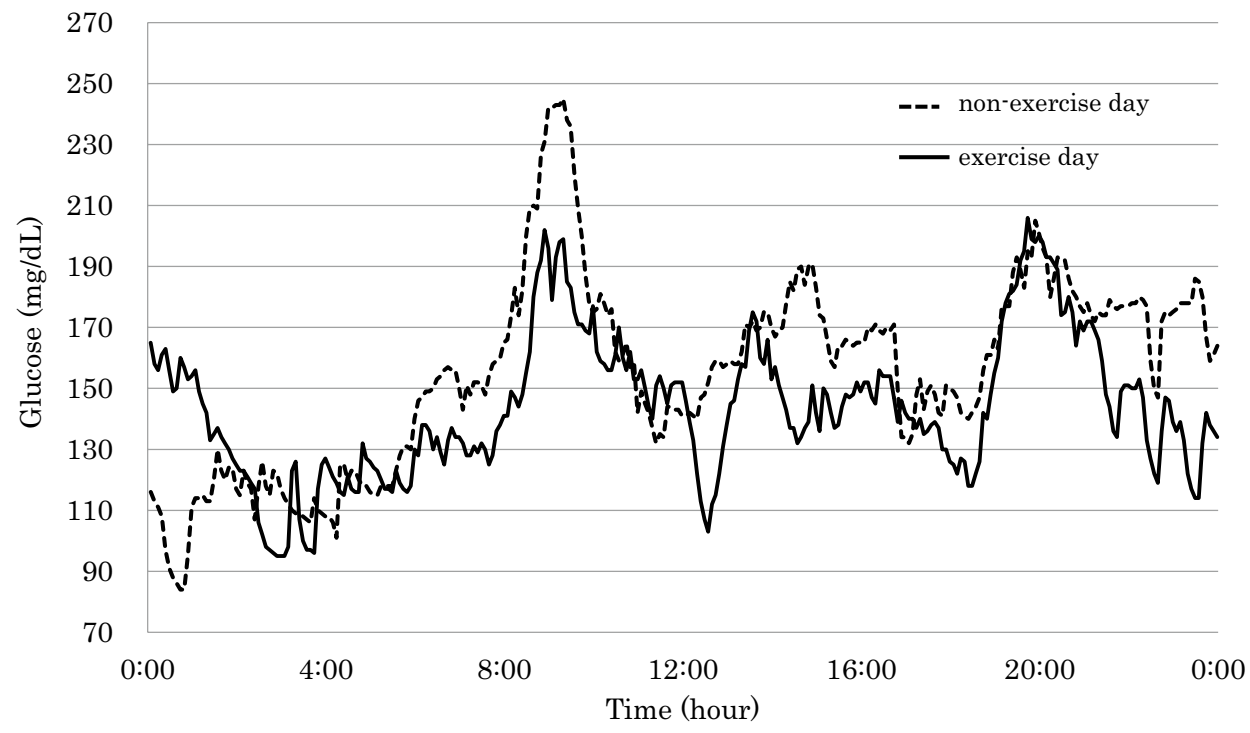

Mild-intensity post meal walking is effective for glucose homeostasis and easy to perform in the daily life of activities of type 2 diabetes patients.

(Drew from reference [12]) 
Fig. 3 Clinical course

Exercise (radio calisthenics 15 min x 2,10,000 steps/day)

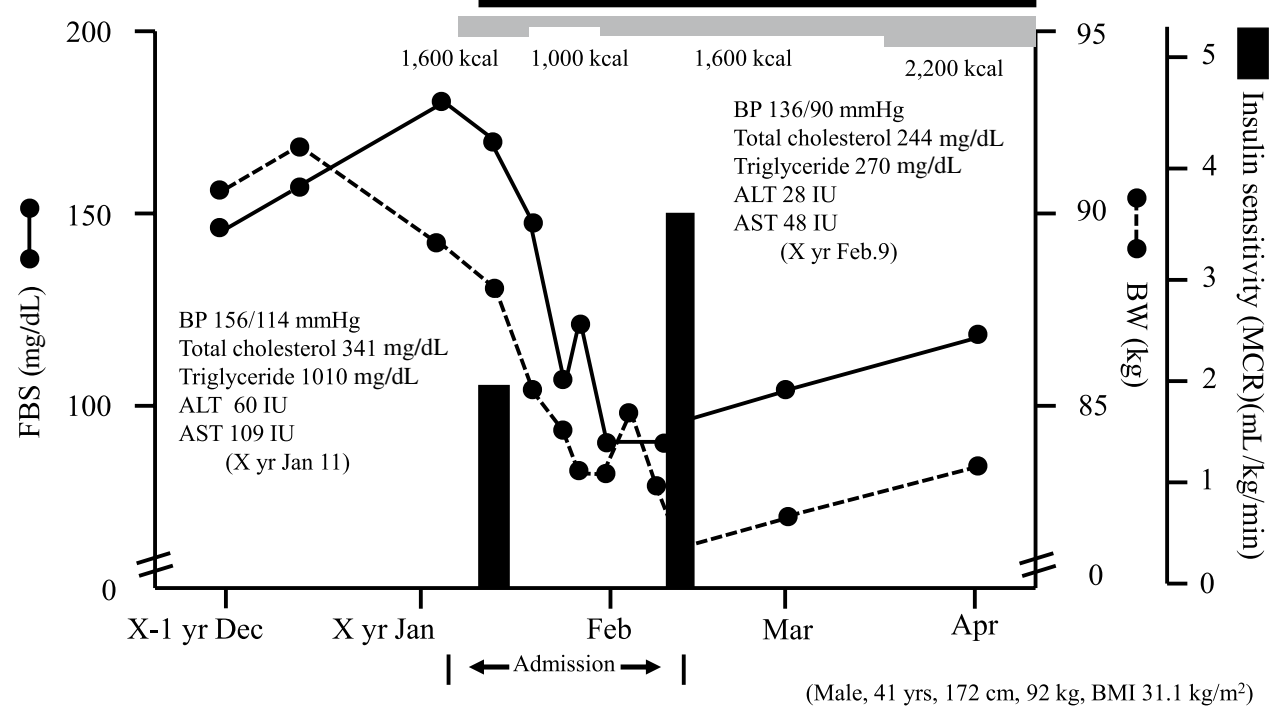

periods of low activity or rest" [4]. Afternoon HIIT was more efficacious than morning HIIT at improving BG in men with type 2 diabetes. Strikingly, morning HIIT had an acute deleterious effect, evidenced by an increase in BG levels [33].

A brief summary of HIIT effects is as follows [4]:

(1) Leads to modest improvements in metabolic control, of similar magnitude to other forms of exercise training.

(2) Should not be overstated for its role in weight loss.

(3) Has strong cardiovascular benefits.

(4) Leads to large improvements in cardiorespiratory fitness, often superior to other forms of exercise training.

Recommendations for HIIT prescription are as follows [4]:

Frequency: 3 HIIT sessions per week.

Intensity: Most easily measured by the rating of perceived exertion (although it may be variable in practice).

Time: Intervals should last between 1 and 4 min, with intervals at the shorter end being preferred by patients. The total time spent doing interval exercise should be 10-20 min per session.

Type: Activities involving a large muscle mass.

\section{Present Condition Of Exercise Therapy For Diabetes Patients In Japan: A Nationwide Survey}

At present, a large number of studies have focused on the utility of exercise intervention for preventing and treating type 2 diabetes $[16,21,27]$. However, the results of those studies are meaningless if the actual prescription of effective exercise therapy is not put into practice by medical institutions. Thus, a nationwide survey on the actual situation of exercise therapy in Japan was conducted by the Japan Diabetes Society to clarify the problems related with this practice (Chairperson: Yuzo Sato, M.D., Ph.D) $[2,32]$.

(1) Dietary guidance was performed to $70-80 \%$ of the diabetes patients at the initial visit, however, only $40 \%$ of the doctors provided exercise guidance to the patients on their initial visit.

(2) Problems related to the exercise therapy guidance for diabetes patients are as follows:

Lack of time to teach, no additional consultation fee, lack of exercise educators, and lack of guidebook on exercise (Fig. 4).

(3) Only half ( $52 \%)$ of the diabetes patients performed regular physical exercise.

(4) Dieticians give dietary guidance. However, exercise specialists such as health fitness programmers and physiotherapists do not take care of exercise guidance and medical doctors instruct on exercise practice to the diabetes patients (Fig. 5).

(5) Walking is the most popular type of exercise. Followed by bicycle, and then resistance training.

(6) Odds ratios of possible factors affecting the "exercise therapy group" in all diabetes patients were investigated by multiple logistic regression analysis. The odds ratio of patients who enjoy doing exercise was 4.9 . It is important to maintain the motivation of the patients to participate in exercise therapies, to increase the frequency of guidance, and to provide more detailed exercise prescription such as frequency and duration of exercise (Table 1). Therefore, it is recommended that physical exercise education should be performed in such a way that diabetes patients enjoy doing exercise. 


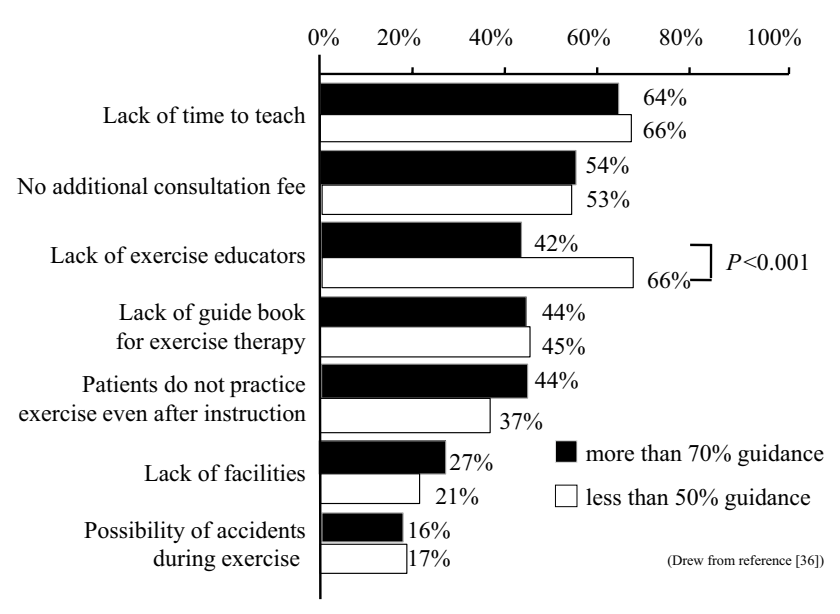

Fig. 4 Problems related to the exercise therapy guidance for diabetes patients (multiple answers)

\section{Exercise Prescription}

Treatment methods of diabetes mellitus are as follows: 1 . diet, 2. exercise, 3. pharmacologic therapy (1) oral drugs, (2) treatment by injection (a) insulin, (b) GLP-1 receptor agonists $[1,15]$.

Among the indicators of glycemic control, $\mathrm{HbAlc}$ is very important and influences the main decisions about treatment. $\mathrm{HbA} 1 \mathrm{c}$ is an indicator that reflects the mean BG level of the patient in the past 1-2 months. In the individual patient, this value shows little daily variation and, therefore, is the most important indicator of overall glycemic control. On the other hand, HbA1c does not give any information on the daily fluctuations of BG. Moreover, there is a number of factors other than BG that affect the level of HbA1c [15].

The BG level is an important metabolic indicator that complements the HbA1c value. For being relatively stable, the fasting $\mathrm{BG}$ is an indicator of metabolic state. On the other hand, the BG level $2 \mathrm{~h}$ after a meal is readily affected by the amount and type of food taken, as well as by the treatment method. It is pointed out to be associated with the risk of cardiovascular disease [15].

When aiming to prevent complications, the $\mathrm{HbA1c}$ target value should be $<7.0 \%$. When therapy intensification is considered difficult due to side effects such as hypoglycemia, the HbA1c level should be $<8.0 \%$ [15].

In type 2 diabetes, by the time of the first consultation retinopathy, nephropathy, neuropathy, or atherosclerotic disorders may already have come to light. Together with the BG control, it is necessary to check for and treat such complications of diabetes [15].

Diabetes is one of the typical lifestyle-related diseases [27]. Medical staff should educate patients about how diabetes develops and progresses and how they can appropriately carry out diet therapy and exercise therapy on their own. $\mathrm{HbA} 1 \mathrm{c}$ as well as BG levels and other metabolic indicators are measured and followed in the context of this treatment and results (improvement of metabolism) are discussed with the patient. According to need, the patient is given guidance for the reinforcement of either or both types of treatment.

If despite the continuation of these treatments for 2 or 3 months, the target value of glycemic control is not achieved, drug treatment is used. This target value differs from patient to patient, but should generally be $\mathrm{HbA} 1 \mathrm{c}$ below $7.0 \%$, excepting aged diabetes patients [15].
Fig. 5 Exercise therapy guidance counselor (multiple answers)

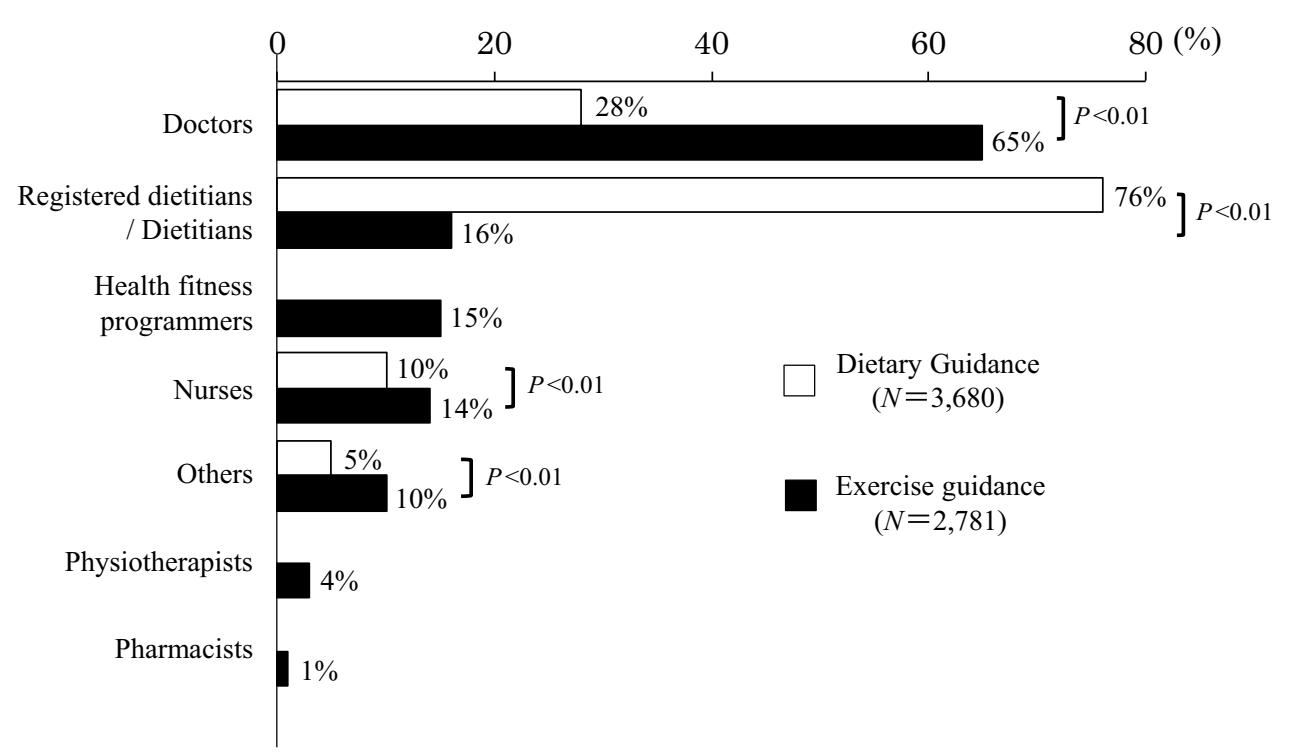

(Drew from reference [2]) 
Table 1 Odds ratios of possible factors affecting the "exercise therapy group" in all participants by multiple logistic regression analysis

\begin{tabular}{|c|c|c|}
\hline Independent variable & $\begin{array}{l}\text { Odds ratios (95\% Confidence } \\
\text { interval) }\end{array}$ & $P$ value \\
\hline No insulin treatment (ref.: insulin treatment) & $1.21(1.00-1.47)$ & 0.011 \\
\hline \multicolumn{3}{|l|}{ Frequency of exercise therapy guidance (ref.: no exercise guidance) } \\
\hline Every medical consultation & $1.79(1.28-2.51)$ & 0.001 \\
\hline Once per $2-5$ medical consultations & $1.89(1.40-2.56)$ & $<0.001$ \\
\hline Once per 6-10 medical consultations & $1.24(0.95-1.63)$ & 0.118 \\
\hline Once a year & $1.23(0.97-1.55)$ & 0.086 \\
\hline Received exercise guidance including type (ref.: no exercise prescription) & $1.32(1.08-1.61)$ & 0.008 \\
\hline Received exercise guidance including frequency (ref.: no exercise prescription) & $1.60(1.24-2.06)$ & $<0.001$ \\
\hline Received exercise guidance including duration (ref.: no exercise prescription) & $1.63(1.32-2.01)$ & $<0.001$ \\
\hline \multicolumn{3}{|l|}{ Patients who enjoy doing exercise (ref.: dislike physical exercise) } \\
\hline Enjoy & $4.87(2.97-7.93)$ & $<0.001$ \\
\hline Somewhat enjoy & $2.81(1.72-4.61)$ & $<0.001$ \\
\hline Neither enjoy nor dislike & $2.18(1.33-3.58)$ & 0.002 \\
\hline Somewhat dislike & $1.77(1.07-2.93)$ & 0.025 \\
\hline \multicolumn{3}{|l|}{ Work and housework of 3-5 Mets (ref.: no activity) } \\
\hline $30 \mathrm{~min}$ & $1.50(1.14-1.96)$ & 0.003 \\
\hline $1 \mathrm{~h}$ & $2.31(1.77-3.03)$ & $<0.001$ \\
\hline More than $2 \mathrm{~h}$ & $1.70(1.29-2.25)$ & $<0.001$ \\
\hline
\end{tabular}

The patients who enjoyed doing exercise had higher odds ratios in the exercise therapy group. Physical exercise instruction should be provided so as to maintain patient motivation

\section{Pre-Exercise Evaluation}

Before undertaking any exercise with intensity greater than brisk walking, sedentary people with type 2 diabetes will likely benefit from an evaluation by a physician. Various medical examinations are needed to confirm that diabetes is well controlled and that the patients do not have progressive severe complications [35].

When exercise should be prohibited or restricted [15].

(1) When metabolic control is extremely poor (fasting BG level over $250 \mathrm{mg} / \mathrm{dL}$, or urinary ketone bodies moderately positive or above).

(2) New hemorrhaging in the ocular fundus caused by proliferative retinopathy (consult an ophthalmologist).

(3) Previously, exercise has been restricted for patients with diabetic kidney diseases [15].

However, at present physical activity is understood not only a healthful lifestyle factor but also as a treatment method to decrease the incidence of chronic kidney disease in diabetes patients [22].

There is no evidence that vigorous-intensity exercise increases the progression rate of diabetic kidney disease, and there appears to be no need of specific exercise restrictions for people with diabetic kidney disease in general [1, 5]. Exercise training increases physical function and QOL in individuals with kidney disease, and may even be undertaken during dialysis sessions. The presence of microalbuminuria per se does not necessitate exercise restriction [6].

(4) Ischemic heart disease and cardiopulmonary disorders (seek advice from a specialist).

(5) Presence of bone or joint disease (seek advice from a specialist).

(6) Acute infectious disease.

(7) Diabetic gangrene.

(8) Severe autonomic neuropathy.

\section{Recommended Physical Activity for People with Diabetes [1]}

Most adults with type 1 and type 2 diabetes should engage in $150 \mathrm{~min}$ or more of moderate-to-vigorous intensity aerobic activity per week, spread over at least 3 days/week, with no more than two consecutive days without activity. Shorter durations (minimum $75 \mathrm{~min} /$ week) of vigorous-intensity or interval training may be sufficient for younger and more physically fit individuals. Adults with type 1 and type 2 diabetes should engage in 2-3 sessions/week of resistance exercise on nonconsecutive days (Table 2). Especially for elderly diabetes patients who tend to have muscle atrophy (sarcopenia), mild-intensity resistance training, such as half squats and calf raise should be performed in addition to aerobic exercise [15, 37]. Further, horseback riding equipment 
$\left(\right.$ Joba $^{\circledR} ;$ Panasonic) $[18]$ and Core training chair ${ }^{\circledR}$ (Panasonic) [38] are also useful for older patients and patients with knee or foot problems. Initial instruction and periodic supervision by qualified health fitness programmers and instructors are recommended for most patients with type 2 diabetes, particularly if they undertake resistance exercise training, to ensure optimal benefits in terms of BG control, BP, lipids, and cardiovascular risk, as well as to minimize the risk of injury [35].

All adults, and particularly those with type 2 diabetes, should decrease the amount of time spent in daily sedentary behavior. Prolonged sitting should be interrupted every 30 min for obtaining BG benefits, particularly in adults with type 2 diabetes [1]. Flexibility training and balance training are recommended 2-3 times/week for older adults with diabetes. Yoga [7] and tai chi [20] may be included based on individual preferences to increase flexibility, muscular strength, and balance.

\section{Precautions When Implementing Physical Exercise [35]}

(1) If dietary changes are not implemented, it is unlikely that appropriate BG control will be achieved. Thus, patients should also be instructed regarding dietary restrictions.

(2) Generally, exercise should be performed after meals.

(3) The insulin dose should be reduced prior to undertaking physical exercise. If exercise extends over a prolonged period of time, dietary supplementation is necessary before, during, and after exercise.

(4) If hypoglycemia occurs during exercise, patients should be advised to have a cola drink or glucose dissolved in lukewarm water. Cookies and/or rice balls are suitable before and after exercise to prevent hypoglycemia. Patients should perform self-monitoring of BG before, during, and after exercise.

(5) According to large-scale trials such as the DPP $[8,16]$ and a nationwide survey in Japan [2], successful lifestyle

Table 2 Exercise prescription (FITT Principle)

\begin{tabular}{ll}
\hline Frequency & $\geq 3-5$ times/weeks \\
Intensity & $50 \% \mathrm{VO}_{2 \max }$ (LT levels) \\
& $(30-50$ years old, heart rate 120 beats/min) \\
& $(60-70$ years old, heart rate 100 beats/min) \\
Time & 150 min or more/weeks \\
& $10-30$ (60) min/days (after meals, $2-3$ times/days) \\
Type & $\begin{array}{c}\text { Aerobic, walking, jogging, swimming, bicycling, } \\
\text { resistance exercise half squat, calf raise (esp.elderly } \\
\text { patients) } \\
\end{array}$ \\
& Make exercise enjoyable \\
& Active life-style education
\end{tabular}

$L T$ Lactate threshold interventions, including the incorporation of goal setting, self-monitoring of training effects, frequent contact by teaching staff, and stepped-care protocols, promote PA [35].

(6) Patients should be instructed to wear appropriate sports shoes and should be provided with appropriate warm-up and cool-down exercises (stretching of the extremities).

(7) These exercise interventions should be provided by a medical support team consisting of physicians, physiotherapists, health fitness programmers and instructors, registered dieticians, pharmacists, and nurses [27].

In conclusion, physical exercise plays a major role in the prevention and control of insulin resistance and type 2 diabetes.

Diabetes patients should engage in $150 \mathrm{~min}$ or more of moderate-to-vigorous intensity aerobic activity per week, spread over at least 3 days/week, with no more than two consecutive days without activity. Persons with type 2 diabetes (especially the elderly) should undertake resistance training at least 2-3 times/week. Diabetes patients should decrease the amount of time spent on daily sedentary behavior.

Individuals with type 2 diabetes are encouraged to increase their total daily unstructured PA (daily movement).

An outline of this monograph was presented at the International Forum on Exercise Prescription 2019, held in Xiamen, China (Sponsored: China Sport Science Society and JiMei University; Organizer: College of Physical Education, JiMei University).

Acknowledgements The research by the author reported herein was supported by Longevity Science Research Grants from the Ministry of Health and Labor of Japan, Grants-in-Aid for Scientific Research from the Ministry of Education, Culture, Sports, Science, and Technology of Japan, Grants from the Descente and Ishimoto Memorial Foundation for the Promotion of Sports Science and from the Manpei Suzuki Diabetes Foundation.

\section{Compliance with Ethical Standards}

Conflict of Interest No potential conflicts of interest relevant to this article were reported.

Open Access This article is licensed under a Creative Commons Attribution 4.0 International License, which permits use, sharing, adaptation, distribution and reproduction in any medium or format, as long as you give appropriate credit to the original author(s) and the source, provide a link to the Creative Commons licence, and indicate if changes were made. The images or other third party material in this article are included in the article's Creative Commons licence, unless indicated otherwise in a credit line to the material. If material is not included in the article's Creative Commons licence and your intended use is not permitted by statutory regulation or exceeds the permitted use, you will need to obtain permission directly from the copyright holder. To view a copy of this licence, visit http://creativecommons.org/licenses/by/4.0/. 


\section{References}

1. American Diabetes Association. Standards of medical care in diabetes-2020. Diabetes Care. 2020;43(Suppl. 1):S54-6.

2. Arakawa S, Watanabe T, Sone H, Tamura Y, Kobayashi M, Kawamori R, Atsumi Y, Oshida Y, Tanaka S, Suzuki S, Makita S, Ohsawa I, Sato Y. The factors that affect exercise therapy for patients with type 2 diabetes in Japan: a nationwide survey. Diabetol Int. 2015;6:19-25.

3. Boulé NG, Weisnagel SJ, Lakka TA, Tremblay A, Bergman RN, Rankinen T, Leon AS, Skinner JS, Wilmore JH, Rao DC, Bouchard C. Effects of exercise training on glucose homeostasis: the HERITAGE family study. Diabetes Care. 2005;28(1):108-14.

4. Cassidy S, Thoma C, Houghton D, Trenell MI. High-intensity interval training: a review of its impact on glucose control and cardiometabolic health. Diabetologia. 2017;60(1):7-23.

5. Chen IR, Wang SM, Liang CC, Kuo HL, Chang CT, Liu JH, Lin HH, Wang IK, Yang YF, Chou CY, Huang CC. Association of walking with survival and RRT among patients with CKD stages 3-5. Clin J Am Soc Nephrol. 2014;9(7):1183-9.

6. Colberg SR, Sigal RJ, Fernhall B, Regensteiner JG, Blissmer BJ, Rubin RR, Chasan-Taber L, Albright AL, Braun B. Exercise and type 2 diabetes: the American College of Sports Medicine and the American Diabetes Association: joint position statement. Diabetes Care. 2010;33(12):e147-67.

7. Cui J, Yan JH, Yan LM, Pan L, Le JJ, Guo YZ. Effects of yoga in adults with type 2 diabetes mellitus: a meta-analysis. J Diabetes Investig. 2017;8(2):201-9.

8. Dempsey PC, Larsen RN, Sethi P, Sacre JW, Straznicky NE, Cohen ND, Cerin E, Lambert GW, Owen N, Kingwell BA, Dunstan DW. Benefits for type 2 diabetes of interrupting prolonged sitting with brief bouts of light walking or simple resistance activities. Diabetes Care. 2016;39(6):964-72.

9. DeFronzo RA, Tobin JD, Andres R. Glucose clamp technique: a method for quantifying insulin secretion and resistance. Am J Physiol. 1979;237(3):E214-E23.

10. Diabetes Prevention Program Research Group, Knowler WC, Fowler SE, Hamman RF, Christophi CA, Hoffman HJ, Brenneman AT, Brown-Friday JO, Goldberg R, Venditti E, Nathan DM. 10- year follow-up of diabetes incidence and weight loss in the diabetes prevention program outcomes study. Lancet. 2009;374(9702):1677-86.

11. Hu FB, Leitzmann MF, Stampfer MJ, Colditz GA, Willett WC, Rimm EB. Physical activity and television watching in relation to risk for type 2 diabetes mellitus in men. Arch Intern Med. 2001;161(12):1542-8.

12. Iida Y, Takeishi S, Fushimi N, Tanaka K, Mori A, Sato Y. The effect of mild-intensity postmeal walking for 15-min on glucose homeostasis in type 2 diabetes mellitus (forecast). Jap J Constitut Med. 2016;78:13-7.

13. International Diabetes Federation. IDF diabetes atlas. 9th ed. Belgium: IDF; 2019.

14. Iwao N, Oshida Y, Sato Y. Regional difference in lipolysis caused by a $\beta$-adrenergic agonist as determined by the microdialysis technique. Acta Physiol Scand. 1997;161(4):481-7.

15. Japan Diabetes Society. Treatment guide for diabetes 20162017. Japan: Bunkodo; 2016.

16. Joseph JJ, Echouffo-Tcheugui JB, Golden SH, Chen H, Jenny NS, Carnethon MR, Jacobs D Jr, Burke GL, Vaidya D, Ouyang P, Bertoni AG. Physical activity, sedentary behaviors and the incidence of type 2 diabetes mellitus: the multi-ethnic study of atherosclerosis (MESA). BMJ Open Diabet Res Care. 2016;4(1):e000185.

17. Kelley GA, Kelley KS. Effect of aerobic exercise on lipids and lipoproteins in adults with type 2 diabetes: a meta-analysis of randomized-controlled trials. Public Health. 2007;121(9):643-55.

18. Kempf K, Altpeter B, Berger J, Reu $\beta$ O, Fuchs M, Schneider M, Gärtner B, Niedermeier K, Martin S. Efficacy of the telemedical lifestyle intervention program TeLiPro in advanced stages of type 2 diabetes: a randomized controlled trial. Diabetes Care. 2017;40(7):863-71.

19. Kitamura I, Takeshima N, Tokudome M, Yamanouchi K, Oshida $\mathrm{Y}$, Sato Y. Effects of aerobic and resistance exercise training on insulin action in the elderly. Geriatr Gerontol Int. 2003;3:50-5.

20. Knowler WC, Barrett-Connor E, Fowler SE, Hamman RF, Lachin JM, Walker EA, Nathan DM, Diabetes Prevention Program Research Group. Reduction in the incidence of type 2 diabetes with lifestyle intervention or metformin. N Engl J Med. 2002;346(6):393-403.

21. Kodama S, Shimano H, Tanaka S, Saito K, Heianza Y, Yamada N, Fujihara K, Ohashi Y, Horikawa C, Sone H. Association between physical activity and risk of all-cause mortality and cardiovascular disease in patients with diabetes. Diabetes Care. 2013;36(2):471-9.

22. Kubota M, Nagasaki M, Tokudome M, Shinomiya Y, Ozawa $\mathrm{T}$, Sato Y. Mechanical horse riding improves insulin sensitivity in elder diabetic patients. Diabetes Res Clin Pract. 2006; 71(2):124-30.

23. Lee I-M, Shiroma EJ, Evenson KR, Kamada M, LaCroix AZ, Buring JE. Accelerometer- measured physical activity and sedentary behavior in relation to all-cause mortality: the women's health study. Circulation. 2018;137(2):203-5.

24. Lee MS, Jun JH, Lim H-J, Lim H-S. A systematic review and meta-analysis of tai chi for treating type 2 diabetes. Maturitas. 2015;80(1):14-23.

25. Li G, Zhang P, Wang J, An Y, Gong Q, Gregg EW, Yang W, Zhang B, Shuai Y, Hong J, Engelgau MM, Li H, Roglic G, Hu Y, Bennett PH. Cardiovascular mortality, all-cause mortality, and diabetes incidence after lifestyle intervention for people with impaired glucose tolerance in the da qing diabetes prevention study: a 23-year follow-up study. Lancet Diabetes Endocrinol. 2014;2(6):474-80.

26. Lin $\mathrm{H}-\mathrm{C}$, Peng $\mathrm{C}-\mathrm{H}$, Chiou J-Y, Huang C-N. Physical activity is associated with decreased incidence of chronic kidney disease in type 2 diabetes patients: a retrospective cohort study in Taiwan. Prim Care Diabet. 2014;8(4):315-21.

27. Look AHEAD Research Group, PI-Sunyer X, Blackburn G, Brancati FL, Bray GA, Bright R, Clark JM, Curtis JM, Espeland MA, Foreyt JP, Graves K, Haffner SM, Harrison B, Hill JO, Horton ES, Jakicic J, Jeffery RW, Johnson KC, Kahn S, Kelley DE, Kitabchi AE, Knowler WC, Lewis CE, Maschak-Carey BJ, Montgomery B, Nathan DM, Patricio J, Peters A, Redmon JB, Reeves RS, Ryan DH, Safford M, Van Dorsten B, Wadden TA, Wagenknecht L, Wesche-Thobaben J, Wing RR, Yanovski SZ. Reduction in weight and cardiovascular disease risk factors in individuals with type 2 diabetes: 1 year results of the Look AHEAD trial. Diabetes Care. 2007;30(6):1374-83.

28. Musi N, Fujii N, Hirshman MF, Ekberg I, Fröberg S, Ljungqvist O, Thorell A, Goodyear LJ. AMP-activated protein kinase (AMPK) is activated in muscle of subjects with type 2 diabetes during exercise. Diabetes. 2001;50(5):921-7.

29. Nagasawa J, Sato Y, Ishiko T. Effect of training and detraining on in vivo insulin sensitivity. Int J Sports Med. 1990;11(2):107-10.

30. Oshida Y, Yamanouchi K, Hayamizu S, Sato Y. Long-term mild jogging increases insulin action despite no influence on body mass index or $\mathrm{VO}_{2 \max }$. J Appl Physiol. 1989;66(5):2206-10.

31. Ravussin E. A neat way to control weight? Science. 2005;307(5709):530-1.

32. Sakane N, Sato J, Tsushita K, Tsujii S, Kotani K, Tsuzaki K, Tominaga M, Kawazu S, Sato Y, Usui T, Kamae I, Yoshida T, Kiyohara Y, Sato S, Kuzuya H, Japan Diabetes Prevention Program 
(JDPP) Research Group. Prevention of type 2 diabetes in a primary healthcare setting: three-year results of lifestyle intervention in Japanese subjects with impaired glucose tolerance. BMC Public Health. 2011;11(1):40-7.

33. Sakane N, Sato J, Tsushita K, Tsujii S, Kotani K, Tominaga M, Kawazu S, Sato Y, Usui T, Kamae I, Yoshida T, Kiyohara Y, Sato S, Tsuzaki K, Takahashi K, Kuzuya H, Japan Diabetes Prevention Program (JDPP) Research Group. Effects of lifestyle intervention on weight and metabolic parameters in patients with impaired glucose tolerance related to beta- 3 adrenergic receptor gene polymorphism $\operatorname{Trp} 64 \operatorname{Arg}(\mathrm{C} / \mathrm{T})$ : results from the Japan diabetes prevention program. J Diabetes Investig. 2016;7(3):338-42.

34. Sato Y, Nagasaki M, Kubota M, Uno T, Nakai N. Clinical aspects of physical exercise for diabetes/metabolic syndrome. Diabetes Res Clin Pract. 2007;77(Suppl 1):S87-91.

35. Sato Y. Clinical aspects of physical exercise for diabetic patients: theory and practice. Showa Univ J Med Sci. 2012;24:259-71.

36. Sato Y, Kondo K, Watanabe T, Sone H, Kobayashi M, Kawamori R, Tamura Y, Atsumi Y, Oshida Y, Tanaka S, Suzuki S, Makita S, Ohsawa I, Imamura S. Present situation of exercise therapy for patients with diabetes mellitus in Japan: a nationwide survey. Diabetol Int. 2012;3(2):86-91.

37. Savikj M, Gabriel BM, Alm PS, Smith J, Caidahl K, Björnholm M, Fritz T, Krook A, Zierath JR, Wallberg-Henriksson H. Afternoon exercise is more efficacious than morning exercise at improving blood glucose levels in individuals with type 2 diabetes: a randomized crossover trial. Diabetologia. 2019;62(2):233-7.

38. Sawada SS, Muto T, Lee I-M, Higaki Y, Naito H, Tanaka H, Noguchi J, Blair SN, Tsukamoto K. Long-term trends in cardiorespiratory fitness and the incidence of type 2 diabetes. Diabetes Care. 2010;33(6):1353-7.

39. Sigal RJ, Kenny GP, Boulé NG, Wells GA, Prud'homme D, Fortier M, Reid RD, Tulloch H, Coyle D, Phillips P, Jennings A, Jaffey J. Effects of aerobic training, resistance training, or both on glycemic control in type 2 diabetes: a randomized trial. Ann Intern Med. 2007;147(6):357-69.

40. Sone H, Tanaka S, Tanaka S, Suzuki S, Seino H, Hanyu O, Sato A, Toyonaga T, Okita K, Ishibashi S, Kodama S, Akanuma Y,
Yamada N, Japan Diabetes Complications Study Group. Leisuretime physical activity is a significant predictor of stroke and total mortality in Japanese patients with type 2 diabetes: analysis from the Japan Diabetes Complications Study (JDCS). Diabetologia. 2013;56(5):1021-30.

41. Tokudome M, Nagasaki M, Shimaoka K, Sato Y. Effects of homebased combined resistance training and walking on metabolic profiles in elderly Japanese. Geriatr Gerontol Int. 2004;4(3):157-62.

42. Tremblay MS, Aubert S, Barnes JD, Saunders TJ, Carson V, Latimer-Cheung AE, Chastin SFM, Altenburg TM, Chinapaw MJM. Sedentary Behavior Research Network (SBRN) -Terminology Consensus Project process and outcome. Int J Behav Nutr Phys Act. 2017;14(1):75-91.

43. Uno T, Nagasaki M, Kajioka T, Sato Y. Acute effects on glucose metabolism in mechanical core training chair. In: Presented at the 61th Annual Meeting of Japan Diabetes Society, Tokyo, 2018.

44. van der Berg JD, Stehouwer CD, Bosma H, van der Velde JH, Willems PJ, Savelberg HH, Schram MT, Sep SJ, van der Kallen CJ, Henry RM, Dagnelie PC, Schaper NC, Koster A. Associations of total amount and patterns of sedentary behaviour with type 2 diabetes and the metabolic syndrome: the maastricht study. Diabetologia. 2016;59(4):709-18.

45. Wahren J, Felig P, Hagenfeldt L. Physical exercise and fuel homeostasis in diabetes mellitus. Diabetologia. 1978;14(4):213-22.

46. Willey KA, Singh MA. Battling insulin resistance in elderly obese people with type 2 diabetes: bring on the heavy weights. Diabetes Care. 2003;26(5):1580-8.

47. Williamson DA, Rejeski J, Lang W, van Dorsten B, Fabricatore AN, Toledo K, Look AHEAD Research Group. Impact of a weight management program on health-related quality of life in overweight adults with type 2 diabetes. Arch Intern Med. 2009;169(2):163-71.

48. Yamanouchi K, Ozawa N, Shinozaki T, Suzuki Y, Chikada K, Maeno H, Nishikawa T, Kato K, Ito K, Oshida Y, Shimizu S, Sato Y. Daily walking combined with diet therapy is a useful means for obese NIDDM patients not only to reduce body weight but also to improve insulin sensitivity. Diabetes Care. 1995;18(6):775-8. 